\title{
Cortical Organization of Language
}

\author{
George A. Ojemann \\ Department of Neurological Surgery, University of Washington, Seattle, Washington 98195
}

\begin{abstract}
Recent data obtained by various methods of clinical investigations suggest an organization of language in the human brain involving compartmentalization into separate systems subserving different language functions. Each system includes multiple essential areas localized in the frontal and temporoparietal cortex of the dominant hemisphere, as well as widely dispersed neurons.

All components of a system are activated in parallel, possibly by ascending thalamocortical circuits. The features peculiar to cerebral language organization include not only the lateralization of essential areas to one hemisphere, but also a substantial variance in the individual patterns of localization within that hemisphere, a variance that in part relates to individual differences in verbal skills.
\end{abstract}

The textbook model of human cortical organization for language has been one of the more durable concepts of neurobiology, little changed over nearly a century and a quarter. According to that model, language is processed serially from decoding in the posterior temporal cortex (Wernicke's area) to motor expression in the posterior inferior frontal lobe (Broca's area) (see Fig. 2; Broca, 1861; Wernicke, 1874; Geschwind, 1970). Findings made over the past two decades suggest that a revision of that model is now in order. While the newer data agree with the older on the importance of the perisylvian cortex of the left hemisphere (of most individuals) for the generation of language, they suggest that models of cortical language organization should include separate systems for different language functions. Each system includes localized frontal and temporoparietal areas as well as neurons widely dispersed elsewhere in the cortex, with the entire system being activated in parallel. In many respects, these new findings related to language in man are similar to those described for organization of other functions in the primate association cortex (Mountcastle, 1978; Goldman-Rakic, 1988). However, two aspects of cortical language organization differ substantially from other findings made in the primate cortex: the long-known lateralization of language functions to one hemisphere (designated as "dominant"), and recent findings

\footnotetext{
My research included in this review is supported by NIH Grants NS 17111, NS 21724, and NS 20482.

Correspondence should be addressed to George A. Ojemann, M.D., Professo of Neurological Surgery, Department of Neurological Surgery, RI-20, University of Washington, Seattle, WA 98195.

Copyright (C) 1991 Society for Neuroscience $0270-6474 / 91 / 112281-07 \$ 03.00 / 0$
}

of a substantial variance in the individual pattern of organization within that hemisphere (G. Ojemann et al., 1989).

The revised model is based on new findings made by diverse approaches to the investigation of cerebral language organization. Until recently, the standard experimental procedures of neurobiology have had little application to the study of language. Although nonhuman primates have been taught quasi-linguistic, nonvocal communication systems of some complexity, the neurobiological basis of these animal models has not been investigated. The neurobiology of species-specific nonhuman primate vocalization has been extensively studied (Jurgens, 1979), but its relation to human language is unclear. All knowledge of the brain organization for language has thus depended on human studies, predominantly in a clinical context. Two types of data are derived from those human studies: One type establishes a link between language and brain organization by associating an altered function in a brain area with a change, usually a deficit, in linguistic behavior. Such data identify a brain area as one whose function is essential for some aspect of language. Examples include studies of aphasia and other changes in linguistic competence after strokes as well as other types of brain damage, and under intraoperative electrical stimulation (Penfield and Roberts, 1959; Ojemann, 1983) and intravascular amobarbital perfusion (Wada and Rasmussen, 1960). The other type of data correlate physiologic studies such as scalp electroencephalograms (Hillyard and Picton, 1987), electrocorticograms and microelectrode recordings during surgical opportunities (Fried et al., 1981; Ojemann et al., 1988), metabolism and blood flow measured by positron emission tomographic (PET), and other isotopic techniques (Ingvar, 1983; Raichle, 1990) with some measure of linguistic performance. Changes in physiologic parameters may be present at sites that are not essential for a language behavior.

Although the PET procedure is recent, most of the other techniques are not: the new findings are attributed mainly to technical improvements (e.g., identification of extent of lesions in the living subject by magnetic resonance imaging) and to development of morc refincd measures of linguistic performance (adapted from cognitive and neuropsychology). Each technique has its limitations. Some techniques can be applied only to particular kinds of patients whose pathological condition may have altered language organization in some unknown way. Temporal instability of findings is a problem with many techniques, because language deficits may change over time after the patient 
suffers a particular brain lesion. Changes in neuronal activity or blood flow accompanying a particular linguistic behavior may vary with repetitions of that behavior (Raichle, 1990; M. Haglund and G. A. Ojemann, unpublished observations). Convergence of data obtained by use of diverse techniques is thus important for reaching reliable conclusions. Nevertheless, findings made by intraoperative techniques, the author's primary area of investigation, will receive spccial cmphasis in this review.

\section{Compartmentalization in Separate Systems}

Evidence that the cortical area dedicated to language is not unitary, but compartmentalized into separate systems for processing different aspects of language, is available from lesion studies (Caramazza, 1988). Both frontal and temporoparietal lesions that disturb only written, and not oral, language have been frequently reported (Benson, 1977), though under the textbook model this deficit (at least for temporoparietal lesions) has been ascribed to disconnection of language from the visual cortical areas (Geschwind, 1970). Moreover, lesion studies have indicated separate areas for handling different languages, because there are lesions in polyglots that leave only one of their multiple languages intact, one that may not even be the mother tonguc, the language most frequently used by the subject, or the language of the subject's environment (Paradis, 1977). Separate areas are also present for handling different grammatical classes of words, as indicated by lesions disturbing only the use of "closed-class" words in syntax (Goodglass, 1976) or only the naming of specific semantic categories, such as "fruits" (Hart et al., 1985) or "animals" but not "tools" (Damasio, 1990).

Intraoperative electrical stimulation of one or the other of two different cortical sites has evoked disturbances in naming the same object in one or the other of two different languages (Ojemann and Whitaker, 1978; Ojemann, 1983; Rapport et al., 1983; Black and Ronner, 1987). This separation of areas dedicated to different languages was evident in both the frontal and the temporoparietal cortex. A functional separation has also been evidenced at sites where stimulation alters naming an object either in an oral language or in a manual communication system (finger spelling: Mateer et al., 1982; American Sign Language: Haglund and Ojemann, unpublished observations). Cortical stimulation mapping of interference with either object naming or reading in 55 subjects showed a separation of evoked changes in these functions at both frontal and temporal sites: $77 \%$ of 111 sites at which stimulation elicits changes in either function showed changes in only one of them (Ojemann, 1989). In 14 subjects, stimulation mapping during tests for object naming, reading of sentences, recent verbal memory, orofacial movement mimicry, and phoneme identification also showed substantial separation of functions; $57 \%$ of 91 sites at which stimulation evoked changes in any function showed changes in only one (G. A. Ojemann and Mateer, 1979; Ojemann, 1983). These included both frontal and temporal cortical sites related only to object naming or only to the syntactic aspects of reading.

Not only do linguistically relevant areas often pertain to different aspects of language, but microelectrode recordings taken intraoperatively from areas where stimulation has no effect also frequently identify neurons that change their activity with the performance of only one of multiple language functions. Sixtyseven percent of the neuronal populations recorded from the left anterior temporal lobe that changed activity during tests for object naming, reading, or verbal memory changed activity dur- ing only one type of test (Ojemann et al., 1988). Five neuronal populations have been recorded from left temporal cortex of three subjects during naming the same objects in either one or the other of two languages and another population in another subject during naming in either oral language or in American Sign Language. All neurons showed changes in activity only upon use of one of the alternative (Ojemann, 1990; Ojemann ct al., 1990; D. Cawthon, G. Ojemann, and E. Lettich, unpublished observations). Thus, the system for a particular language function includes both essential areas and widely dispersed neurons, dispersed even to the nondominant hemisphere (Creutzfeldt et al., 1989a,b; J. Ojemann, G. Ojemann, and E. Lettich, unpublished observations). All of these features have been shown for the separate systems related to object naming (including separate systems for naming in different languages), reading, and recent verbal memory, suggesting that human association cortex has a modular organization, with a system of essential areas and widely dispersed neurons the module repeated for different language-related functions (Ojemann, 1990).

The functional unit that constitutes a system is still under investigation. As the data presented above indicate, different linguistic functions, such as naming in general, and naming different categories of objects in particular, as well as reading in gencral, and the syntactic aspect of language, are subserved at least partly by separate systems; so are mechanisms subserving naming in two different languages. Substantial evidence from lesion studies, stimulation mapping, and neuronal activity recording also indicates that recent verbal memory is a separate system (Milner, 1971; Ojemann, 1983; Ojemann and Dodrill, 1985; Ojemann et al., 1988). The situation in regard to speech production and speech perception is less clear. These are the two language functions that are traditionally separated in the textbook model. However, stimulation mapping disrupts sequential orofacial movements used in speech production and the identification of speech sounds at many of the same cortical sites, in the perisylvian cortex of left inferior frontal, left parietal, and superior temporal lobes (G. A. Ojemann and Mateer, 1979; Ojemann, 1983). This finding supported the psycholinguistically derived concept of Liberman et al. (1967), that speech sound decoding requires creation of a motor model (the motor theory of speech perception) and thus the existence of a common module for language production and perception. On the other hand, only a few neurons have been identified that change their activity in the same way during speech perception and production (Ojemann et al., 1990). These few neurons were located in the left superior temporal gyrus. Many more neurons were found in the superior and middle temporal gyri (of either hemisphere) that change activity only either during speech perception or during speech production, but not with both conditions (Creutzfeldt et al., 1989a,b); this separation is present even though the same word is heard in either condition, said aloud by someone else in one condition, and said aloud by oneself in the other. Except in experimental settings, linguistic performance usually requires continual shifting between systems: speaking or reading, syntax or semantics, one semantic category or another, one language or another

The cortical anatomic distribution of the essential portion of these systems also differs from the concepts of the textbook model; in addition, neuronal activity related to a system may be much more widespread than the essential areas. Essential areas of systems related to speech production include not only the traditionally recognized area in the posterior inferior frontal 
cortex immediately anterior to the facial motor cortex, but also the inferior parietal and superior temporal gyri, as revealed by both stimulation-mapping (G. A. Ojemann and Mateer, 1979; Ojemann, 1983) and lesion (Mohr, 1976) studies. Based on stimulation mapping, systems related exclusively to naming or reading seem to be adjacent to that cortex related to speech production, both temporally and frontally (Ojemann, 1983). The temporal areas solely related to naming identified by that technique correspond closely to sites of lesions producing anomic aphasia, a language deficit pertaining only to naming (Benson, 1979), while left inferior frontal areas active during a semantic task (generating verbs from nouns), but not during speech production, have been identified by PET (Petersen et al., 1988, 1989). A cortical system identified by stimulation-mapping studies as related exclusively to recent verbal memory surrounds the sites related exclusively to naming or reading, frontally and temporoparietally. Effects on recent verbal memory produced by left anterior temporal resections have been related to this cortical memory representation (Ojemann and Dodrill, 1985, 1987), and changes in neuronal activity during recent verbal memory tests have been recorded in the same area (Ojemann et al., 1988). It has been suggested that specialized language functions arose phylogenetically between a lateralized perisylvian motor control system for sequential orofacial movements and a lateralized cortical recent-memory system (G. Ojemann and Mateer, 1979). Although the perisylvian cortex of the dominant hemisphere is generally considered to be the essential area that subserves language, there is also evidence for a role in language production for the supplementary motor area in the superior frontal cortex based on lesion studies (Rostomily et al., 1991), stimulation mapping (Penfield and Roberts, 1959), and blood flow and PET analyses (Ingarv, 1983; Petersen et al., 1989).

The extent of the essential portions of one of the systems in the adult dominant hemisphere cortex has been studied in most detail for object naming. Essential areas for naming are commonly localized by intraoperative stimulation mapping to one or more rather small cortical surface areas of $1-2 \mathrm{~cm}^{2}$ (G. Ojemann et al., 1989; Fig. 1). In a series of 117 subjects examined by stimulation mapping of their dominant perisylvian cortex during naming, two or more such areas separated by cortex not related to language were identified in two-thirds of the cases, and three or more separate areas in $24 \%$ of the cases (G. Ojemann et al., 1989). Usually, at least one area was in the inferior frontal gyrus, and one or more were in the temporoparietal cortex. Most often these areas had sharp boundaries. A few had fuzzy boundaries, with a transition zone where stimulation produced occasional rather than regular disruptions of naming (Whitaker and Ojemann, 1978). The estimated total surface area of essential sites was rather small, $2.5 \mathrm{~cm}^{2}$ or less in $50 \%$, and exceeding $6 \mathrm{~cm}^{2}$ in only $16 \%$ of the 117 subjects (G. Ojemann et al., 1989). Because the extent of the essential frontal and temporoparietal perisylvian language cortex under the textbook model exceeds $8 \mathrm{~cm}^{2}$ (Fig. 2) (Penfield and Roberts, 1959), that model is likely to be based on an artifact of pooling data from subjects whosc cssential areas are in different locations, and thus an overestimate of the extent of essential modules for one language function in an individual brain.

Essential language areas seem to be preferentially localized in the crown of gyri, and are rarely buried entirely in sulci. Although well over half of human perisylvian cortex is buried in sulci, surface stimulation mapping of perisylvian cortex iden-

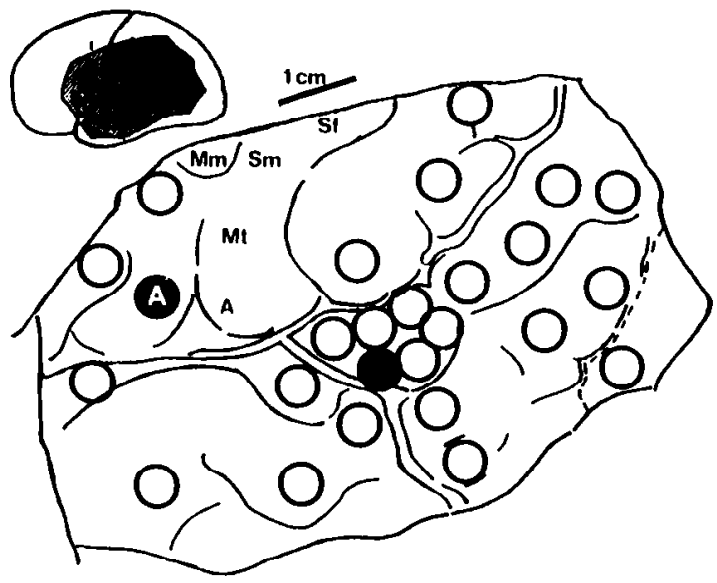

Figure 1. Location of two sites at which stimulation altered naming in left, dominant hemisphere of a 36-yr-old female subject. Circles are sites of bipolar stimulation through electrodes separated by $5 \mathrm{~mm}$, using trains of biphasic square-wave pulses at $60 \mathrm{~Hz}$, of $2.5 \mathrm{msec}$ total duration, and $4 \mathrm{~mA}$ between pulse peaks. Solid circles, sites of repeated naming errors; open circles, no errors. Solid circle labeled $A$, naming errors, predominantly arrest of speech; other solid circle, anomia. Letters outside of the circles indicate evoked motor $(M m, M t, A)$ and sensory $(S m, S f)$ responses identifying Rolandic cortex. The shaded area in the inset indicates the location of intraoperative cortical exposure. Note site of repeated naming errors in superior temporal gyrus and lack of errors at immediately surrounding sites [from Ojemann, 1988; additional examples of localized essential areas for naming with sharp boundaries are presented in Ojemann $(1983,1991)$ and in G. Ojemann et al. (1989)].

tified at least one essential area for language in nearly all subjects ( 117 of 119 nonaphasic, left-brain-dominant cases in one series; G. Ojemann et al., 1989). These surface sites are a reliable predictor of whether a resection that includes buried cortex will or will not disturb language (Ojemann, 1983). Moreover, in the few cases in which the relation of language to buried cortex was examined by stimulation mapping, separate buried sites were not identified, and surface sites either extended only a short distance into adjacent buried cortex (including the planum temporale), or stopped at the edge of a sulcus (G. Ojemann et al., 1989).

\section{Variance}

Studies of many different subject populations have shown a remarkable variance in brain organization for language. This variance begins with the gross anatomy of human left perisylvian cortex. Recent studies have found a major variability in the gyral pattern at the end of the sylvian fissure (Rubens et al., 1976; Steinmetz et al., 1990), in the extent of the planum temporale (the cortex buried in sylvian fissure posterior to primary auditory cortex; Geschwind and Levitsky, 1968), and in the extent of its specific cytoarchitectonic areas (Galaburda et al., 1978). The relative sizes of the right and left planum temporale have been correlated with the lateralization of language with the result that the planum temporale tends to be larger in the hemisphere bearing the cortical areas dedicated to language (Geschwind and Levitsky, 1968).

Variance is evident in the functional lateralization of language, as well. Assessment of language lateralization under intracarotid amobarbital perfusion indicates that $5 \%$ of subjects have bilateral cortical language areas; in $4 \%$ these areas are lateralized on the right, and in the remainder, on the left (Woods 


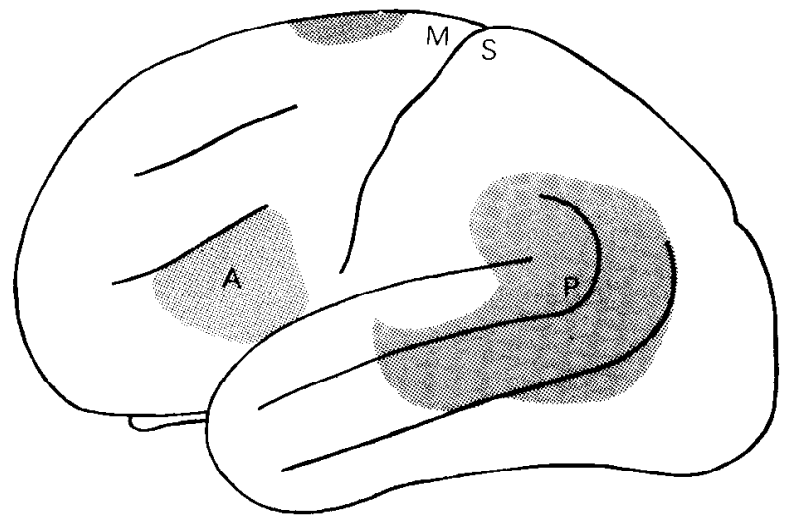

Figure 2. Location of essential cortical areas for language in the traditional textbook model, here as presented in Penfield and Roberts (1959), are indicated by shading. $A$, frontal (Broca's) language area; $P$, posterior (Wernicke's language area); $M$ and $S$, motor and sensory cortex. Compare to language localization in an individual subject (Fig. 1) and variance in that localization across a population (Fig. 3 ).

et al., 1988). Provided that subjects who are left-handed because of left hemisphere frontal or parietal damage are excluded from the survey, there is no relation between left-handedness and language lateralization (Woods et al., 1988). After major damage to left frontal or parietal lobe in infancy, language will develop in the right hemisphere. Although language is functional in such subjects, it is not entirely normal, suffering from a limited syntactic competence compared to normal subjects or subjects with right-hemisphere damage in infancy (Dennis and Whitaker, 1976). The upper age limit of this ability of the right hemisphere to subserve language has not been definitively established, with diverse estimates ranging from less than $3 \mathrm{yr}$ of age (Woods, 1983) to more than 6 yr of age (Penfield and Roberts, 1959).

A substantial variance in location of essential language areas is also evident within the left hemisphere of adults with the usual left-brain lateralization of language (G. Ojemann et al., 1989). In 90 subjects undergoing stimulation mapping in both frontal and temporoparietal cortex during the object-naming test, no frontal perisylvian essential areas could be identified in $15 \%$, and only frontal (and no temporoparietal) areas in another $17 \%$. As indicated in Figure 3, essential areas were consistently identified only in the inferior frontal gyrus immediately in front of the facial motor cortex, but even there, in the traditional Broca's area, stimulation evoked no language changes in $21 \%$ of the subjects. In the superior temporal gyrus, essential areas were identificd in $65 \%$ of the subjects, but their location varicd from within $3 \mathrm{~cm}$ of the tip of the temporal lobe, well in front of the level of the Rolandic cortex, to the most posterior extent of the superior temporal gyrus. As is evident from Figure 3, no region of Wernicke's traditional posterior language area showed essential sites in over $36 \%$ of these subjects. A similar difficulty in consistently localizing the posterior language areas has been described in stroke patients (Bogen and Bogen, 1975). Substantial variance in the location of areas where deficits in reading are evoked was also evident by stimulation mapping, especially in the temporoparietal cortex (Ojemann, 1989).

Different patterns of localization of essential areas for language functions have been related to the subject's sex and verbal abilities, as measured by the verbal IQ (VIQ; Ojemann, 1989; G. Ojemann et al., 1989). In studies of stimulation mapping during object naming, women were more likely to have essential

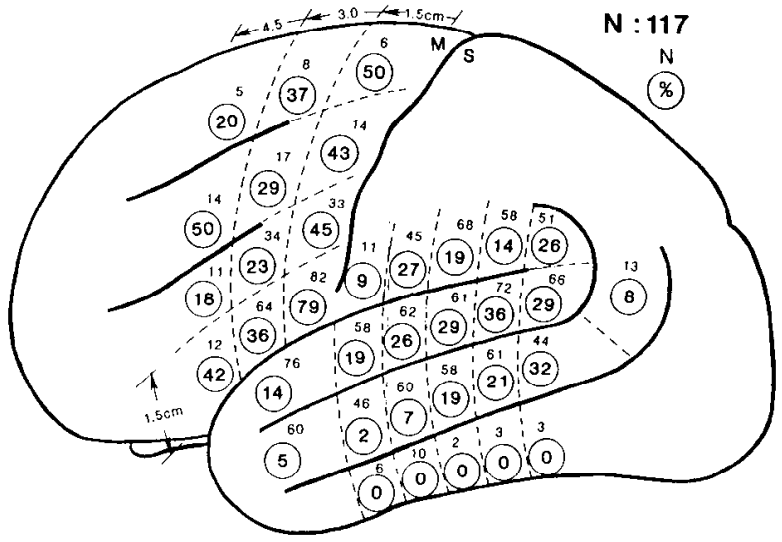

Figure 3. Variability in localization of sites essential for naming, based on electrical stimulation mapping in left, language-dominant hemisphere of 117 patients. Individual maps, such as Figure 1, were aligned with reference to Rolandic cortex and end of Sylvian fissure. The cortex was then divided into zones represented by intersecting solid and broken lines. The upper number in each zone indicates the number of subjects in whom a site was tested in that zone; the lower circled number indicates the percentage of those subjects in whom naming errors were evoked at sites in that zone. $M$ and $S$ indicate motor and sensory cortex, respectively. From G. Ojemann et al. (1989).

sites only in the frontal lobes. Among subjects with a lower VIQ, women were less likely to have perisylvian parietal essential sites than men (G. Ojemann et al., 1989). Evidence of less extensive posterior language representation in women has also been provided by lesion studies (Kimura, 1983). The most robust relation between verbal abilities, as assessed by preoperative VIQs and location of essential areas, was identified in studies of stimulation mapping during object naming and reading tests (Ojemann, 1989): Higher VIQs were associated with a combination of areas related only to naming in the middle temporal gyrus and related only to reading in the superior temporal gyrus, with the reverse pattern obtaining in patients with lower VIQs. There was no relation between VIQ and the location of areas related to both naming and reading. In addition, the total surface area related to naming appeared to be smaller in subjects with higher VIQs. There is thus a relation between organization of the language cortex and language abilities.

The extent to which developmental factors or experiences account for this high variance in pattern of perisylvian language organization that in part relates to verbal abilities has not been fully ascertained. The high variance in local gyral anatomy presumably reflects a genetic polymorphism, and some of this anatomic variance has been identified in the fetus (Wada et al., 1975). However, the variance in functional localization of language is greater than the anatomic variance. Highly localized essential areas for naming have been identified with the stimulation mapping techniques in the youngest patients investigated, at age 4 (G. Ojemann et al., 1989). The location of these areas in children from 4 to $10 \mathrm{yr}$ of age has been about as variable as in adults. Older children (of about $8 \mathrm{yr}$ ) are more likely to show multiple temporoparietal essential areas (G. Ojemann, unpublished observations); otherwise, there is little difference in patterns or organization of essential naming sites determined by stimulation mapping in the youngest $(4 \mathrm{yr})$ to oldest $(80 \mathrm{yr})$ subjects (G. Ojemann et al., 1989). The location of essential areas in adults did not change over time in the few cases in which remapping was undertaken without an intervening brain 
lesion (Ojemann, 1983), nor has any relation between the intrahemispheric topography of language areas and the location of acquired brain damage been evident in patients with intact language (G. Ojemann et al., 1989). Although these findings do not indicate a topographic effect of linguistic experience, patterns of localization of two languages in the same subject do suggest some such effect. Essential areas for naming in a lateracquired language in which the subject was less fluent were larger than those for naming in an earlier acquired, more fluent language (Ojemann and Whitaker, 1978; D. Cawthon, unpublished observations). Fluency of command of the language was more clearly related to the severity of the naming deficit evoked by stimulation with a more severe deficit evoked in the more fluent language (Cawthon, unpublished observations). There is insufficient experience with stimulation mapping of subjects speaking different languages to determine whether any localization pattern is characteristic for any particular language(s). However, most languages (including manual communication systems and pictographic languages) are lateralized in the left hemisphere, according to data from lesion and intracarotid amobarbital perfusion studies (Bellugi et al., 1983; Paradis, 1990).

\section{Parallel Processing}

The various components of the cortical system for a language function appear to be activated in parallel. This parallel activation includes frontal and temporoparietal essential areas, as well as the more widely dispersed neurons that belong to the system. There is little, if any, physiologic evidence to support the textbook model of serial processing from posterior to anterior language areas, whereas parallel processing is suggested by a convergence of data obtained by diverse observations. Parallel processing has been inferred from the pattern of behavioral changes after brain lesions (Caramazza, 1988; Damasio, 1990) and language-activated PET scans (Raichle, 1990), and demonstrated directly by electrocorticographic changes that occur at sites essential for naming during naming (Fried et al., 1981; G. A. Ojemann et al., 1989), and by microelectrode recordings at nonessential sites during various language tasks (Ojemann, 1990).

Electrocorticograms recorded during naming tasks showed slow potentials at frontal sites and local "desynchronization" [replacement of alpha rhythm activity $(7-12 \mathrm{~Hz})$ by low-voltage, high-frequency activity] at temporoparietal sites (Fried et al., 1981; G. A. Ojemann et al., 1989). Both changes were evident shortly after presentation of the object to be named, and lasted throughout the approximately $1 \mathrm{sec}$ required for naming. Desynchronization was most often maximal at sites in the temporal cortex in the 700-1200-msec period following stimulus presentation (G. A. Ojemann et al., 1989). Such electrocorticographic recordings differentiated from surround cortex sites independently identified as essential for naming by stimulation mapping. Moreover, desynchronization was absent when the same visual stimuli used for naming were presented in a spatial matching task. The shifts in frequency of neuronal activity during naming or reading most commonly recorded by microelectrodes at nonessential sites in the temporal lobe occurred at the onset of the task and were sustained for several seconds (Ojemann et al., 1988, 1990; Ojemann, 1989, 1990). Both increases and decreases in frequency have been identified.

The electrocorticographic change recorded at frontal cortical sites during naming - a slow potential of 1 -sec duration - is most likely a motor prepotential. It is present during overt speech, but also when naming is done silently. It thus provides a physiologic marker for "inner speech" and indicates that language processing in that setting includes effector readiness (Fried et al., 1981). Both frontal slow potentials and local desynchronization are electrocorticographic changes that have been related to activity of the thalamocortical activating system (Jasper, 1960; Skinner and Yingling, 1987). Sustained shifts in frequency of cortical neuronal activity may also reflect such ascending influence, which would activate the cortical system appropriate for a given language function, including essential areas and widely dispersed neurons activated in parallel. The intensity of this activation seems to be greater at essential areas.

\section{Subcortical Mechanisms}

In the past two decades, views have also changed on the role of subcortical structures in language, especially of thalamus and striatum. The textbook model held (though not without controversy) that striatial structures were important in language production (Marie, 1906), while the thalamus was thought to have no role other than general arousal (Nielsen, 1946). However, latter-day studies indicate more specific linguistic roles of subcortical structures, in addition to integrating motor and respiratory substrates of speech (Ojemann and Van Buren, 1967; Ojemann, 1975). Modern imaging techniques have identified focal lesions in thalamus and striatum of the dominant hemisphere in patients with language deficits (Reynolds et al., 1979; Damasio et al., 1982; Naeser et al., 1982; Graff-Radford et al., 1985). The language deficits associated with thalamic lesions, unlike those associated with any cortical lesion, consist of a disproportionate disturbance of naming, presenting as perseveration on linguistically correct words or phases that are unrelated to the correct name (Reynolds et al., 1979). Stimulation mapping in the left lateral thalamus identified a process common to both language and recent verbal memory that is involved in selective attention to verbal material in the external environment (Ojemann, 1975, 1985; Hugdahl et al., 1990). Failure of this process to sustain continuous attention during language performance may account for the linguistic deficits resulting from thalamic lesions. Subcortical structures subserving language include also the cerebellum. Recent PET studies show increased blood flow in the right cerebellar hemisphere upon performance of a purely linguistic task, generating verbs from nouns (Raichle, 1990). Deficits in this linguistic task and not other aspects of language were present in one subject with right cerebellar damage (Fiez et al., 1990).

The manner of interaction of subcortical components with language function remains to be determined, being one of many unresolved problems in the evolving modern model of the brain organization for language. Other problems include determining why a particular cortical area is essential for a system: Is it, perhaps, a node of convergence of activity from the widely dispersed cortical neurons? The features of those widely dispersed cortical neurons are also subjects for further investigation: Are their specific activity patterns indicative of specific aspects of language, such as individual words, as has been suggested (Creutzfeldt et al., 1989a,b)? Does the observation that nearby neurons are often related to different systems indicate a topographic disposition facilitating the development of linguistic associations?

To fathom the brain organization of languages, future studies should be based on a model that includes multiple modular cortical systems, each specific to some particular aspect of lan- 
guage and comprising several essential areas localized in the frontal and temporoparietal cortex, as well as widely dispersed neurons, all activated in parallel. These studies will be impeded, however, by the considerable extent of individual variance in cortical language organization, a diversity in brain organization that is likely to account for some of the individual differences in verbal skills.

\section{References}

Bellugi U, Poizner H, Klima E (1983) Sign language aphasia. Hum Neurobiol 2:155-170.

Benson D (1977) The third alexia. Arch Neurol 34:327-331.

Benson DF (1979) Neurologic correlates of anomia. Stud Neurolinguist 4:293-328.

Black P, Ronner S (1987) Cortical mapping for defining the limits of tumor resection. Neurosurgery 20:914-919.

Bogen J, Bogen G (1975) Wernicke's region-where is it? Ann NY Acad Sci 280:834-843.

Broca P (1861) Remarques sur le siège de la faculté du langage articulé, suivies d'une observation d'aphémie (perte de la parole). Bull Soc Anat 36:330-357.

Caramazza A (1988) Some aspects of language processing revealed through the analysis of acquired aphasia: the lexical systems. Annu Rev Neurobiol 11:395-421.

Creutzfeldt O, Ojemann G, Lettich E (1989a) Neuronal activity in human lateral temporal lobe. I. Responses to speech. Exp Brain Res $77: 451-475$.

Creutzfeldt O, Ojemann G, Lettich E (1989b) Neuronal activity in human lateral temporal lobe. II. Responses to the subjects own voice. Exp Brain Res 77:476-489.

Damasio A (1990) Synchronous activation in multiple cortical regions: a mechanism for recall. Semin Neurosci 2:287-296.

Damasio A, Damasio H, Rizzo M, Varney N, Gersh F (1982) Aphasia and nonhemorrhagic lesions in the basal ganglia and internal capsule. Arch Neurol 39:15-20.

Dennis M, Whitaker H (1976) Language acquisition following hemidecortication. Linguistic superiority of the left over the right hemisphere. Brain Lang 3:404-433.

Fiez J, Petersen S, Raichle M (1990) Impaired habit learning following cerebellar hemorrhage: a single-case study. Soc Neurosci Abstr $16: 287$.

Fried I, Ojemann GA, Fetz EE (1981) Language-related potentials specific to human language cortex. Science 212:353-356.

Galaburda A, Sanides F, Geschwind N (1978) Human brain cytoarchitectonic left-right asymmetries in the temporal speech region. Arch Neurol 35:812-817.

Geschwind N (1970) The organization of language and the brain. Science 170:940-944.

Geschwind N, Levitsky W (1968) Human brain left-right asymmetries in the temporal speech region. Science 161:186-187.

Goldman-Rakic PS (1988) Topography of cognition: parallel distributed networks in primate association cortex. Annu Rev Neurosci 11: $137-156$.

Goodglass H (1976) Agrammatism. Stud Neurolinguist 1:237-260.

Graff-Radford N, Damasio H, Yamada T, Eslinger P, Damasio A (1985) Non-hemorrhagic thalamic infarction: clinical, neurophysiological and electrophysiological findings in four anatomic groups defined by $\mathrm{CT}$. Brain 108:485-516.

Hart J, Berndt R, Caramazza A (1985) Category-specific naming deficit following cerebral infarction. Nature 316:439-440.

Hillyard S, Picton T (1987) Electrophysiology of cognition. In: Handbook of physiology, Sec I, The nervous system, Vol 5, Higher functions of the brain (Mountcastle V, Plum $\Gamma$, Geiger S, eds), pp 519584. Bethesda, MD: American Physiological Society.

Hugdahl K, Wester K, Asbjornsen A (1990) The role of the left and right thalamus in language asymmetry: dichotic listening in Parkinson patients undergoing stereotactic thalamotomy. Brain Lang 39:1-13.

Ingvar D (1983) Serial aspects of language and speech related to prefrontal cortical activity. A selective review. Hum Neurobiol 2:177189.

Jasper HH (1960) Unspecific thalamocortical relations. In: Handbook of physiology: neurophysiology. Washington, DC: American Physiological Society.
Jurgens U (1979) Neural control of vocalization in nonhuman primates. In: Neurobiology of social communication in primates (Steklis H, Raleigh M, eds), pp 11-44. New York: Academic.

Kimura D (1983) Sex differences in cerebral organization for speech and praxic functions. Can J Psychol 37:19-35.

Liberman AM, Cooper FS, Shankweiler DP, Studdert-Kennedy M (1967) Perception of the speech code. Psychol Rev 74:431-461.

Marie P (1906) Révision de la question de l'aphasie. Semin Med 2: 241-247, 493-500, 565-571.

Mateer CA, Polen SB, Ojemann GA, Wyler AR (1982) Cortical localization of finger spelling and oral language: a case study. Brain Lang 17:46-57.

Milner B (1971) Disorders of learning and memory after temporal lobe lesions in man. Clin Neurosurg 19:421-446.

Mohr JP (1976) Broca's area and Broca's aphasia. Stud Neurolinguis 1:201-236.

Mountcastle V (1978) An organizing principle for cerebral function: the unit module and the distributed system. In: The mindful brain (Edelman G, Mountcastle V, eds), pp 7-50. Cambridge, MA: MIT Press.

Naeser M, Alexander M, Helm-Estrabrooks N, Levin H, Laughlin S, Geschwind N (1982) Aphasia with predominantly subcortical lesion sites-description of three capsular/putaminal aphasia syndromes. Arch Neurol 39:2-14.

Nielsen JM (1946) Agnosia, apraxia, aphasia: their value in cerebral localization, 2d ed. New York: Haeber.

Ojemann G (1990) Organization of language cortex derived from investigations during neurosurgery. Semin Neurosci 2:297-305.

Ojemann G (1991) Cortical organization of language and verbal memory based on intraoperative investigations. Prog Sens Physiol, in press.

Ojemann G, Dodrill CB (1987) Intraoperative techniques for reducing language and memory deficits with left temporal lobectomy. In: Advances in epileptology, Vol 16 (Wolf $P$, Dam M, Janz D, Dreifuss F, eds), pp 327-330. New York: Raven.

Ojemann G, Mateer C (1979) Cortical and subcortical organization of human communication: evidence from stimulation studies. In: Neurobiology of social communication in primates (Stehklis H, Raleigh M, eds), pp 111-132. New York: Academic.

Ojemann G, Van Buren J (1967) Respiratory, heart rate and GSR response from human diencephalon. Arch Neurol 16:74-88.

Ojemann G, Ojemann J, Lettich E, Berger M (1989) Cortical language localization in left-dominant hemisphere. J Neurosurg 71:316-326.

Ojemann G, Cawthon D, Lettich E (1990) Localization and physiological correlates of language and verbal memory in human lateral temporoparietal cortex. In: Neurobiology of higher cognitive functions (Scheibel A, Wechsler A, eds), pp 185-202. New York: Guildford.

Ojemann GA (1975) Language and the thalamus: object naming and recall during and after thalamic stimulation. Brain Lang 2:101-120.

Ojemann GA (1983) Brain organization for language from the perspective of electrical stimulation mapping. Behav Brain Sci 6:189230.

Ojemann GA (1985) Enhancement of memory with human ventrolateral thalamic stimulation: effect evident on a dichotic listening task. Appl Neurophysiol 48:212-215.

Ojemann GA (1988) Effect of cortical and subcortical stimulation on human language and verbal memory. In: Language, communication and the brain (Plum F, ed), pp 101-115. New York: Raven.

Ojemann GA (1989) Some brain mechanisms for reading. In: Brain and reading (Von Euler $C$, Lundberg 1 , Lennerstrand $G$, eds), pp 4759. New York: MacMillan.

Ojemann GA, Dodrill CB (1985) Verbal memory deficits after left temporal lobectomy for epilepsy. J Neurosurg 62:101-107.

Ojemann GA, Mateer C (1979) Human language cortex: localization of memory, syntax and sequential motor-phoneme identification systems. Science 205:1401-1403.

Ojemann GA, Whitaker HA (1978) The bilingual brain. Arch Neurol 35:409-412.

Ojemann GA, Creutzfeldt O, Lettich E, Haglund M (1988) Neuronal activity in human lateral temporal cortex related to short-term verbal memory, naming and reading. Brain 111:1383-1403.

Ojemann GA, Fried I, Lettich E (1989) Electrocorticographic (ECoG) correlates of language. I. Desynchronization in temporal language cortex during object naming. Electroencephalogr Clin Neurophysiol 73:453-463. 
Paradis M (1977) Bilingualism and aphasia. Stud Neurolinguistics 3: 65-122.

Paradis M (1990) Language lateralization in bilinguals: enough already! Brain Lang 39:576-586.

Penfield W, Roberts L (1959) Speech and brain mechanisms. Princeton: Princeton UP.

Petersen S, Fox P, Posner M, Mintun M, Raichle M (1988) Positron emission tomographic studies of the cortical anatomy of single word processing. Nature 331:585-589.

Petersen S, Fox P, Posner M, Mintun M, Raichle M (1989) Positron emission tomographic studies of the processing of single words. $J$ Cogn Neurosci 1:153-170.

Raichle M (1990) Exploring the mind with dynamic imaging. Semin Neurosci 2:307-315.

Rapport RL, Tan CT, Whitaker HA (1983) Language function and dysfunction among Chinese- and English-speaking polyglots: cortical stimulation, Wada testing and clinical studies. Brain Lang 18:342366.

Reynolds A, Turner P, Harris A, Ojemann G, Davis L (1979) Left thalamic hemorrhage with dysphasia: a report of five cases. Brain Lang 7:62-73.

Rostomily RC, Berger MS, Ojemann GA, Lettich E (1991) Postoperative deficits and functional recovery following removal of tumors involving the dominant hemisphere supplementary motor area. J Neurosurg, in press.
Rubens AB, Mahowald MW, Hutton JT (1976) Asymmetry of the lateral (sylvian) fissures in man. Neurology 26:620-624.

Skinner J, Yingling C (1977) Central gating mechanisms that regulate event-related potentials and behavior: a neural model for attention. Prog Clin Neurophysiol 1:30-69.

Steinmetz H, Ebeling U, Huang Y, Kahn T (1990) Sulcus topography of the parietal opercular region: an anatomic and MR study. Brain Lang 38:515-533.

Wada J, Rasmussen T (1960) Intracarotid injections of sodium amytal for the lateralization of cerebral speech dominance. J Neurosurg 17: 266-282.

Wada J, Clarke R, Hamm A (1975) Cerebral hemispheric asymmetry in humans. Cortical speech zones in 100 adults and 100 infant brains. Arch Neurol 32:239-246.

Wernicke C (1874) Der aphasische Symptomenkomplex. Breslau: Cohen and Weigart.

Whitaker HA, Ojemann GA (1978) Graded localization of naming from electrical stimulation mapping of left cerebral cortex. Nature 270:50-51.

Woods BT (1983) Is the left hemisphere specialized for language at birth? Trends Neurosci 6:115-117.

Woods R, Dodrill C, Ojemann G (1988) Brain injury, handedness and speech lateralization in a series of amobarbital studies. Ann Neurol 23:510-518. 